\title{
Impacts of bridge piers on the initiation of ice cover - an experimental study
}

\author{
Jun Wang ${ }^{1}$, Fayi Shi ${ }^{1}$, Pangpang Chen ${ }^{1}$, Peng $\mathrm{Wu}^{2}$, Jueyi Sui ${ }^{3 *}$ \\ ${ }^{1}$ Hefei University of Technology, 193 Tunxi Road, Hefei, Anhui, China. \\ ${ }^{2}$ University of Regina, 3737 Wascana Pkwy, Regina, SK, Canada. \\ ${ }^{3}$ University of Northern British Columbia, 3333 University Way, Prince George, BC, Canada. \\ *Corresponding author. E-mail: jueyi.sui@unbc.ca
}

\begin{abstract}
Ice jams in northern rivers during winter period significantly change the flow conditions due to the extra boundary of the flow. Moreover, with the presence of bridge piers in the channel, the flow conditions can be further complicated. Ice cover often starts from the front of bridge piers, extending to the upstream. With the accumulation of ice cover, ice jam may happen during early spring, which results in the notorious ice jam flooding. In the present study, the concentration of flowing ice around bridge piers has been evaluated based on experiments carried out in laboratory. The critical condition for the initiation of ice cover around bridge piers has been investigated. An equation for the critical floe concentration was developed. The equation has been validated by experimental data from previous studies. The proposed model can be used for the prediction of formation of ice cover in front of a bridge pier under certain conditions.
\end{abstract}

Keywords: Arch-shaped congestion; Bridge pier; Ice cover; Ice floe concentration; Pier distance.

\section{INTRODUCTION}

Ice cover and ice jams occur very often in rivers in the northern hemisphere during frigid winter times. During the formation of an ice cover, water level varies dramatically because of channel blockage and additional resistance to the flow under an ice cover. If a lot of ice floes accumulate under ice cover, then ice jam will be initiated. The depth of water under ice jam depends primarily on the specific discharge per unit width and the backwater effects of the jam itself.

Generally, the process for river freeze-up depends on the surface water velocity or the Froude number, based on the flow depth of the open-water flow approaching the jam. Based on field observations at the Hequ Reach of the Yellow River, Sui et al. $(2002,2005)$ claimed that an average Froude number of 0.09 was found for the river to freeze-up at the Hequ Reach. Specifically, the frontal edge of the ice jam at the Hequ Reach in the Yellow River will extend further upstream only if the flow Froude number $(F r)$ at the upper end of the jam is less than 0.09; the ice jam will not propagate upstream if $F r>0.09$. The approaching flow Froude number can be calculated as following:

$$
F r=\frac{v}{\sqrt{g h}}
$$

where $h$ is mean depth of water in front of ice jam head; $g$ is gravitational acceleration and $v$ is mean flow velocity in front of ice jam head.

In winter, the existence of an ice cover in river can be classified as the following stages, 1) initial covering, 2) stable covering and 3) river break up (Shen, 2010). With the presence of bridge piers or abutments in rivers, flow field and boundary conditions in river channels will be significantly changed. As a consequence, it will impact the initial covering stage of river ice. The transportation of flowing ice in the vicinity of bridge abutments/piers will be significantly affected. As reported by many researchers, ice jams and ice dams have been often formed around bridge abutments and piers because of bridge infrastructures during formation of ice cover and river break up in early spring which would result in a high risk of ice flooding (Beltaos, 1995).

Some issues regarding interaction between ice cover and bridge infrastructures have been addressed in the past few years (Sui et al., 2010; Wu et al., 2014, 2015). However, no systematic research work has been conducted to study the movement of ice floes (or ice cubes) around bridge piers and abutments. Ackermann and Shen (1983) considered the shear stress among ice floes in the numerical simulation, and pointed out that the ice floe discharge in rivers does not have a linear relationship with the surface ice concentration during the initial covering stage. Maximum ice discharge, which is the volume of ice per second at a certain cross section, was used as the criteria for determining whether or not the covering stage will be initiated in rivers. Equations have been developed for the prediction. Calkins and Ashton (1975), Tatinclaux and Lee (1978) conducted experimental research regarding the initiation of ice cover in long straight channels as shown in Figure 1. According to Calkins and Ashton (1975), in their experimental study, the relationship between $L$ (length of ice floe) and $b$ (width of opening of the contraction) is $0.14<L / b<0.5$. However, Tatinclaux and Lee (1978) used $0.15<L / b<0.4$. The role of opening width (b) at the contracted section has been discussed. Regression analysis was conducted to develop the following equation for determining the critical concentration of flowing ice floes:

$$
C^{*}=a_{O}\left(\frac{L}{b}\right)^{-a_{1}},
$$

where $a_{0}$ and $a_{1}$ are determined by the ice jam characteristics, which can be determined from regression analysis. According to Calkins and Ashton (1975), $a_{0}=0.01, a_{1}=2.56$, while according Tatinclaux and Lee (1978), $a_{0}=0.037, a_{1}=1.10$ and $a_{0}=0.032, a_{1}=1.48$, respectively. $C^{*}$ is also affected by the upstream Froude Number of flow approaching bridge piers. In their experimental research, flow velocity was kept lower than the critical velocity for ice floe to be submerged under ice cover. Hence, the flow Froude number is relative smaller. 


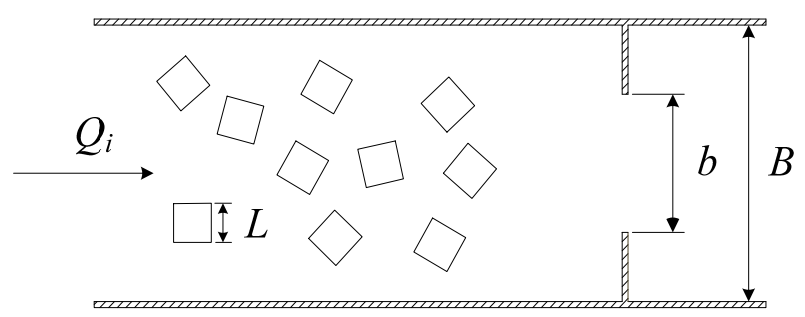

Fig. 1. Ice floe congestion in experiment flume (from Calkins and Ashton, 1975 and Tatinclaux et al., 1978).

To date, very limited research work has been reported regarding the impacts of bridge piers on the movement and accumulation of ice floes around bridge piers. By using Polyurethane block to simulate ice floe, Urroz et al. (1994) conducted experimental research work on the influence of bridge piers on the ice transport capacity when the channel is covered. They noticed the location of bridge pier was an important factor for the ice floe transport in channels. Tyminski (2010) conducted experimental study to investigate the impacts of bridge pier shapes on the movement of ice floe in channel. Seven types of bridge piers were used as shown in Figure 2. By measuring the flow field around piers, they claimed that type 6 was the most suitable pier for reducing the possibility of ice jamming in front of bridge piers.

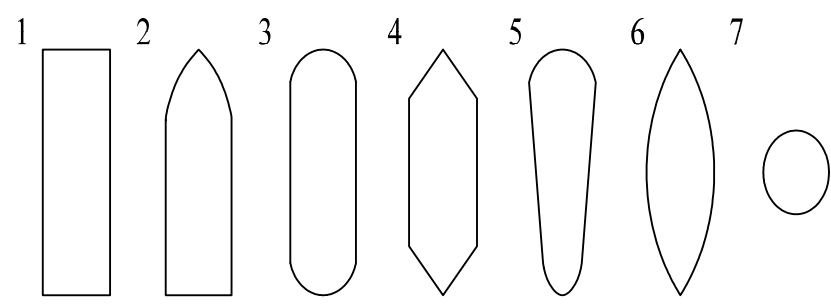

Fig. 2. Pier shapes used by Tyminski (2010).

Carstensen (2012) also conducted an experimental study on the initiation of ice jam around bridge piers. The flow velocity was also kept lower than the critical flow velocity of ice floes to be submerged under ice cover. However, some different results were noticed comparing to results of Tyminski (2010) due to following different experiment setup, 1) the cross section was trapezoidal shape comparing to the rectangular shape in the previous study; 2) the ice floes were designed with different sizes, which can be treated as non-uniform; 3) the initial covering stage was defined as "no floating ice floes were detected from upstream in 30 seconds". By using critical floe concentration $\left(C^{*}\right)$ as the indicator, the upstream ice floe density can be described as: $C_{i}=Q_{i} /\left(V_{0} \cdot B_{L}\right)$, where $\mathrm{B}_{\mathrm{L}}$ is the bottom width of the trapezoidal cross section. Carstensen (2012) pointed out that under the condition of the same $L / W_{L}$ (where $L$ is the characteristic length of ice floe, and $W_{L}$ is the distance between 2 adjacent bridge piers - pier distance), the larger the size of uniform ice floe, the larger the critical flowing ice concentration $C^{*}$. Moreover, with non-uniform ice floe, if the median grain size length of the non-uniform ice floes equals to the characteristic length of the uniform ice floe, larger ice floe can yield a larger $C^{*}$. In other words, ice jam can be easily initiated with large non-uniform ice floes.

So far, all research work reported regarding the impacts of bridge piers on the movement and accumulation of ice floes around bridge piers is just based on experiments. No theoretical analysis and mathematical derivation has been reported. In present study, the critical condition for the initiation of ice cover around bridge piers has been investigated based on both theoretical analysis and experimental study. Equation for the critical concentration of ice floe for initiating an ice cover has been developed. Calculated results by using developed equation have been compared to those of our experiments and experiments of other researchers.

\section{EXPERIMENTAL SETUP}

To study the critical concentration of flowing ice for initiating an ice cover around bridge piers, the present experimental study was conducted by using flowing ice floes in a flume in the Ice Hydraulics Laboratory at the Hefei University of Technology, China. Figure 3 shows the flume setup in this laboratory, which has a width of $40 \mathrm{~cm}$. The model ice floe was made from polypropylene with average mass density of $0.918 \mathrm{~g} / \mathrm{cm}^{3}$, which is close to the mass density of natural ice of $0.917 \mathrm{~g} / \mathrm{cm}^{3}$. As pointed out by Kawai et al. (1997), ice in rivers normally has either the quadrilateral shape or the pentagon shape. Therefore, the following sizes of model ice floes were selected in the present study, with dimensions of $2 \mathrm{~cm} \times 2 \mathrm{~cm} \times 1 \mathrm{~cm}$ and $3 \mathrm{~cm} \times 3 \mathrm{~cm} \times 1 \mathrm{~cm}$, respectively. The water depths of approaching flow used in the research were: $10 \mathrm{~cm}, 15 \mathrm{~cm}, 20 \mathrm{~cm}$ and $25 \mathrm{~cm}$, respectively. The average flow velocities of approaching flow were $0.05 \mathrm{~m} / \mathrm{s}, 0.07 \mathrm{~m} / \mathrm{s}, 0.09 \mathrm{~m} / \mathrm{s}, 0.11 \mathrm{~m} / \mathrm{s}, 0.13 \mathrm{~m} / \mathrm{s}$, $0.15 \mathrm{~m} / \mathrm{s}$ and $0.17 \mathrm{~m} / \mathrm{s}$, respectively. The pier models have a diameter of $2 \mathrm{~cm}$, which were placed at the cross section 16 .

Ice floes were discharged into the flume by the ice floe discharger located at the upstream section of the flume, as shown Figure 3. By adjusting the ice floe discharger and water depth, turbulence flow has been minimized. The distance from upstream of flume to the experimental zone was kept long enough to ensure that ice floe has the same velocity as that of water surface. Additionally, to avoid ice floe reversing and diving into the water, smaller flow velocities were maintained in the present study. Two Plexiglas cylinders with a diameter of $2 \mathrm{~cm}$ were used to simulate double bridge pier. The pier models were placed at section 16 with equal distances of spacing.

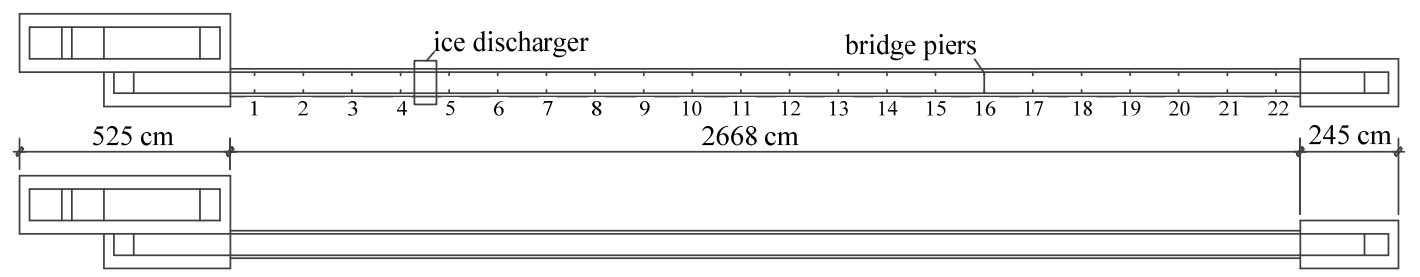

Fig. 3. The experimental flume setup in the laboratory. 

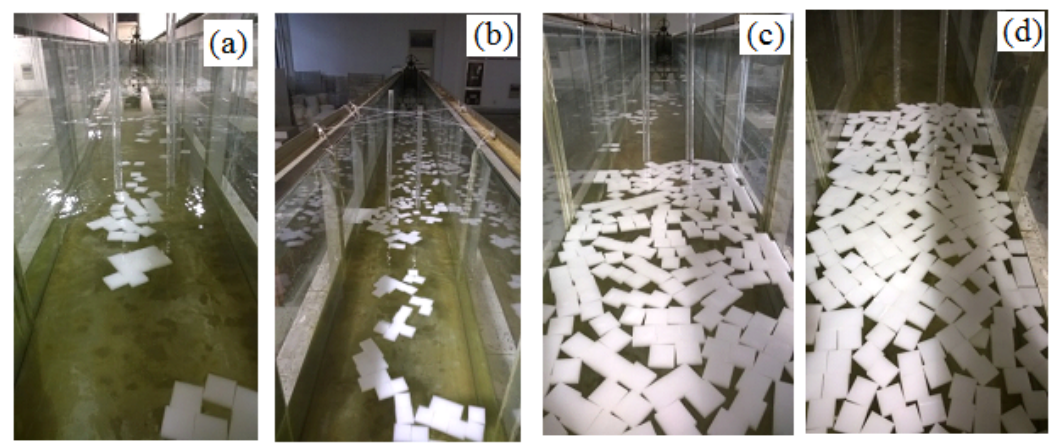

Fig. 4. The congestion of ice floe (or formation of ice cover) in front of two bridge piers in laboratory.

\section{EQUATION FOR INITIATING AN ICE COVER}

In natural rivers, the majority of ice floes is floating on water surface and transported from upstream to downstream provide the flow velocity is relatively low. When some ice floes approach bridge piers, under certain circumstance, such as low flow velocity, the arch-shaped congestion of ice floes may occur in front of bridge piers. This phenomenon can either occur during river freeze-up process or river break-up process. Figure 5 shows the arch-shaped congestion of ice floes formed in our experiment in laboratory. One can see from Figure 5 that the arch-shaped congestion of ice floes in front of bridge piers in our experiment is very similar to the curve shown in Figure 6 (proposed by Kawai et al., 1997).
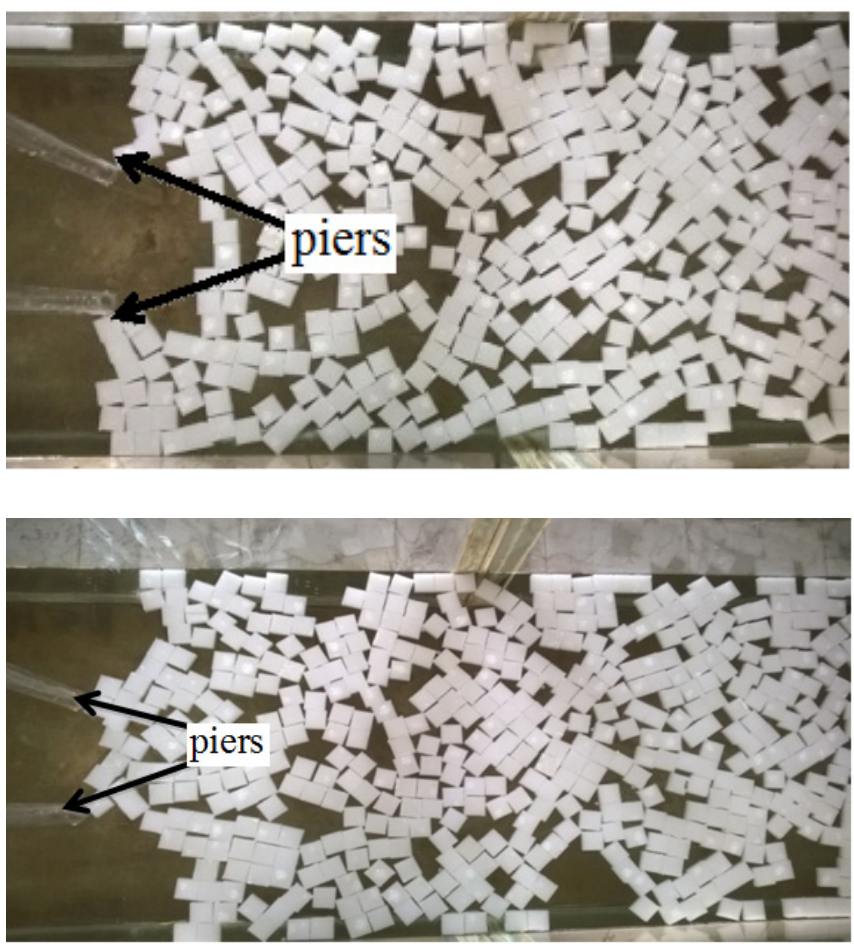

Fig. 5. The arch-shaped congestion of ice floe in the laboratory.

Conceptually, forces acting on each ice floe consist of followings: drag force, lifting force, gravity force, friction forces between ice floes, and hydrodynamic pressure force, as shown in Figure 7. Special attention should be paid on the cohesive force and drag force exerted by wind in natural channels. During river break-up, the cohesive force can be neglected while during initial covering stage (or early freeze-up of river) and stable covering stage, the cohesive has a clear impact on ice accumulation.

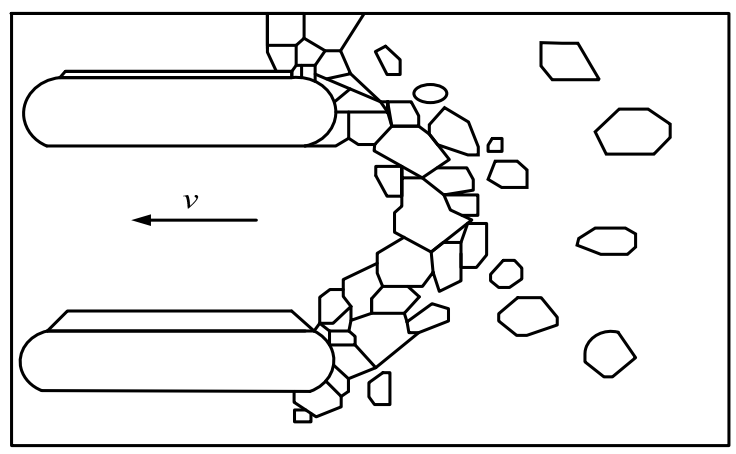

Fig. 6. Conceptual arch-shaped congestion of ice floe in front of piers (Kawai et al., 1997).

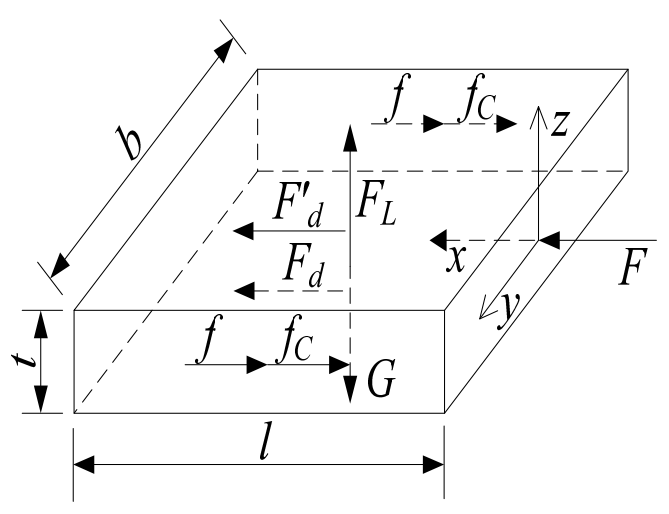

Fig. 7. Force analysis on an ice floe.

As shown in Figure 7, the hydrodynamic pressure force $F=\frac{1}{2} C_{D} \rho v^{2} b t$, where, $C_{D}$ is the hydrodynamic pressure coefficient, $f$ is the friction forces acting on an ice floe, $f_{C}$ is the cohesive force. $F_{d}=\frac{1}{2} C_{S} \rho v^{2} b l$ shows the drag force of ice floe, where $C_{S}$ is the drag coefficient. $F_{d}^{\prime}=\frac{1}{2} C_{S}^{\prime} \rho_{a} v^{\prime 2} b l$ is the drag force acted by wind, in which $C_{S}{ }_{S}$ is the drag coefficient from wind, $v^{\prime}$ is the wind speed, $\rho_{a}$ is the mass density of air. $G=\rho_{i} g t b l$ is the gravity force of ice floe. $F_{L}=s_{i} \rho g t b l$ is the lifting force acted on an ice floe, in which, $t$ is the thickness of ice floe, $l$ and $b$ are the length and width of ice floe, 
respectively. $\rho$ is mass density of water and $\rho_{i}=s_{i} \rho, \rho_{i}$ is mass density of ice floe, in which $s_{i}$ is the specific gravity. $g$ is the gravitational acceleration. As indicated by (Beltaos, 1995), the value of $C_{D}$ is between 0.2 and 0.4 , while $C_{S}$ is about 0.075 .

According to Long et al. (2000), forces acting on an ice floe can be calculated as:

$$
F_{H}=\frac{q L^{2}}{8 h}
$$

If the flow velocity was kept as a constant, forces acting on an ice floe in the horizontal direction are drag force and hydrodynamic pressure. Meanwhile, by considering the shear stress among ice floes, the uniform distributed load on ice floe can be expressed as:

$q=\frac{\beta \rho_{i} v^{2} l b C}{B}$

In which, $B$ is the channel width, $\beta$ is the contraction coefficient caused by piers, $C$ is the surface floe concentration. Hence, the friction forces acting on an ice floe can be calculated as:

$$
f=\lambda k_{0} \rho_{i} v^{2} l b C
$$

In which, $k_{0}=\frac{L^{2}}{8 h B} \beta$ is the horizontal pressure coefficient and $\lambda$ is the friction coefficient among ice floes.

In the following paragraph, condition of critical concentration is used, during which the ice jam is initiated. From the force analysis as shown in Figure 7, one can see that, in the horizontal direction, if the total force of friction force and cohesive force is larger than sum of drag forces (caused by both flow and wind) and hydrodynamic forces, the arch-shaped congestion of ice floe can be formed. It can be described as following:

$$
2\left(f+f_{c}\right) \geq F_{d}+F_{d}^{\prime}+F
$$

By substituting each force as discussed before, Eq. 6 can be derived as following:

$$
2\left(\lambda k_{0} C \rho_{i} v^{2} l b+f_{c}\right) \geq \frac{1}{2} C_{s} \rho v^{2} l b+\frac{1}{2} C_{S}^{\prime} \rho_{a} v^{\prime 2} l b+\frac{1}{2} C_{D} \rho v^{2} t b
$$

Simplify the above equation as:

$$
C \geq \frac{1}{2 \lambda k_{0} \rho_{i} v^{2} l b}\left(\frac{1}{2} C_{S} \rho v^{2} l b+\frac{1}{2} C_{S}^{\prime} \rho_{a} v^{\prime 2} l b+\frac{1}{2} C_{D} \rho v^{2} t b-2 f_{c}\right)
$$

Here, we define $C^{*}$ as the critical concentration of ice floe for initiating an ice jam. If $C>C^{*}$, then the ice jam can be initiated.

$$
C^{*}=\frac{1}{2 \lambda k_{0} \rho_{i} v^{2} l b}\left(\frac{1}{2} C_{S} \rho v^{2} l b+\frac{1}{2} C_{S}^{\prime} \rho_{a} v^{\prime 2} l b+\frac{1}{2} C_{D} \rho v^{2} t b-2 f_{c}\right)
$$

In this experimental study, both the cohesive force and wind drag force can be neglected. For natural rivers, the drag force can be determined using field experimental data. Cohesive force can be calculated according to Beltaos (1995). Hence, Eq. 9 can be simplified as:

$$
C^{*}=\frac{C_{S}}{4 \lambda k_{0} s_{i}}\left(1+\frac{C_{D} t}{C_{S} l}\right)
$$

Eq. 10 indicates that the critical floe concentration is affected not only by ice characteristics but also by physical conditions of ice floes. Eq. 10 has similar relationship to that conclusion drawn by Tatinclaux and Lee (1978). It is also necessary to mention that, the arch-shaped congestion of ice floe has strong connection with pier-distance of spacing (between 2 adjacent piers) and pier diameter. The value of $k_{0}$ is changing accordingly. The channel width $B$, pier diameter $d$ and pier-distance will have significant impact on the critical concentration of ice floe for initiating an ice jam. Under the conditions of the same parameters as well as same thickness of arch-shaped congestion of ice floe, relationship between critical concentrations of ice floe for initiating an ice jam for 2 ice floes with different thickness can be yielded as following:

$$
C_{1}^{*}=C_{2}^{*}\left(1+\frac{C_{D} t_{1}}{C_{S} l_{1}}\right) /\left(1+\frac{C_{D} t_{2}}{C_{S} l_{2}}\right)
$$

\section{RESULTS AND DISCUSSIONS}

The concentration of ice floe can be adjusted by discharging ice floes into the flume from upstream. The arch-shaped congestion of ice floe can be observed around bridge piers. Therefore, the critical concentration of ice floe for initiating an ice jam can be reached.

\section{Results}

At the beginning of each experiment, the ice floe moved from upstream of the pier towards downstream. Due to the blockage of bridge piers, the velocities of ice floes upstream of bridge piers were decreased. With the continuous congestion of ice floes from upstream, the concentration of ice floe around bridge piers increases. When the concentration of ice floe is larger than the concentration of ice floes transported to downstream, the arch-shaped congestion of ice floe occurred. In contrast, ice accumulation under the congested ice cover (or ice jam) will be formed. Figure 4 shows the congestion process of ice floe during experiments. Following findings have been noted:

(a) During the beginning stage of congestion of ice floes, ice floes move from upstream interacting with each other. Hence, the moving velocity of ice floe decreases;

(b) With the increase in the amount of ice floe from upstream, the concentration of ice floe around bridge piers is increasing;

(c) Due to the decrease in ice floe transportation, ice floes were congested in front of bridge piers, what results in the formation of an ice cover;

(d) With the presence of ice cover in front of bridge piers, no ice floes can be detected moving from upstream. However, with an increase in flow velocity, ice floes in front of ice cover are able to be submerged under ice cover and accumulated to form ice jam. 
By running experiments under different flow depths and flow velocities, it is found that the presence of bridge piers can significantly affect the transportation of ice floes in river channels as shown in Figure 4. Ice floes transported from upstream interact with each other and also with bridge piers which have a significant impact on the velocity field around bridge piers. Due to the decrease in flow cross-section area, the transportation rate of ice floe to downstream in the vicinity of bridge pier is significantly reduced, which results in the formation of ice jam. With an increase in moving ice floe in channel, it is very likely that an ice jam will be formed around bridge piers.

According to Tatinclaux and Lee (1978), the surface concentration of ice floe can be determined as following:

$$
C=\frac{Q_{i}}{t_{i} v B},
$$

where $C$ is the surface concentration of ice floes, $t_{i}(\mathrm{~m})$ is the thickness of ice floe, $B(\mathrm{~m})$ is the channel width, $v(\mathrm{~m} / \mathrm{s})$ is the upstream approaching flow velocity and $Q_{i}\left(\mathrm{~m}^{3} / \mathrm{s}\right)$ is the ice floe discharge (the ratio of ice floe volume to time period). By using Equation 12, the relationship of flow velocity and surface floes concentration is shown in Figures 8 and 9.

From Figures 8 and 9, one can say that the critical concentration of ice floe is 0.25 and 0.165 for ice floe of $2 \mathrm{~cm} \times 2 \mathrm{~cm}$ $\times 1 \mathrm{~cm}$ and $3 \mathrm{~cm} \times 3 \mathrm{~cm} \times 1 \mathrm{~cm}$, respectively. If the ice floe concentration is less than the critical value, ice cover cannot be formed in rivers. Comparing these experimental results, the following conclusion can be drawn, under the condition of the same pier diameter and pier-distance, the critical concentration of ice floe is the main factor affecting the formation of an ice jam in front of bridge piers. Meanwhile, the critical concentration of ice floe is also affected by the size of ice floe. It means, a larger size of ice floe has a higher risk for resulting in initiating an ice jam around bridge piers.

\section{Validation of model and discussion}

From Eq. 11, it can be found that, under the same flow conditions and boundary conditions (such as $B, d$, pier-distance), the formation of an ice jam can be predicted based on the existing data. By using data collected for ice floes of $2 \mathrm{~cm} \times 2 \mathrm{~cm}$ $\times 1 \mathrm{~cm}$, together with Eq. 12 proposed by Tatinclaux and Lee (1978), the equation for the critical concentration of ice floe is validated as Table 1 .

It can be noted from Table 1 that, the calculated results by using Eq. 11 is reasonable close to the experimental data. If the channel width, pier diameter and pier-distance are known, it is possible to predict whether or not the channel will be covered in front of the bridge piers by using above approach. It should be noted that Eq. 11 is based on the assumption of the same arch-shaped congestion of ice floes. It means that, different sizes of ice floes can yield different arch-shaped congestion of ice floes, which is the reason for the minor difference between experimental results and calculated results. Hence, when ice floes have larger size, the impact of arch-shaped congestion of ice floes has to be considered.

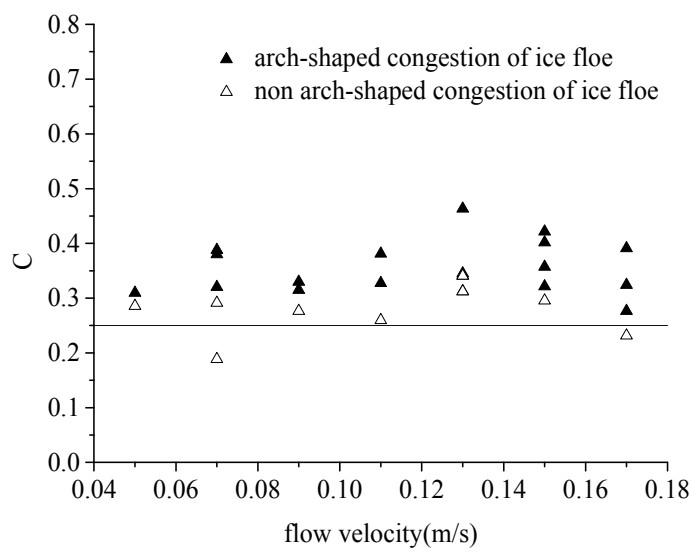

(a) $\mathrm{H}=10 \mathrm{~cm}$

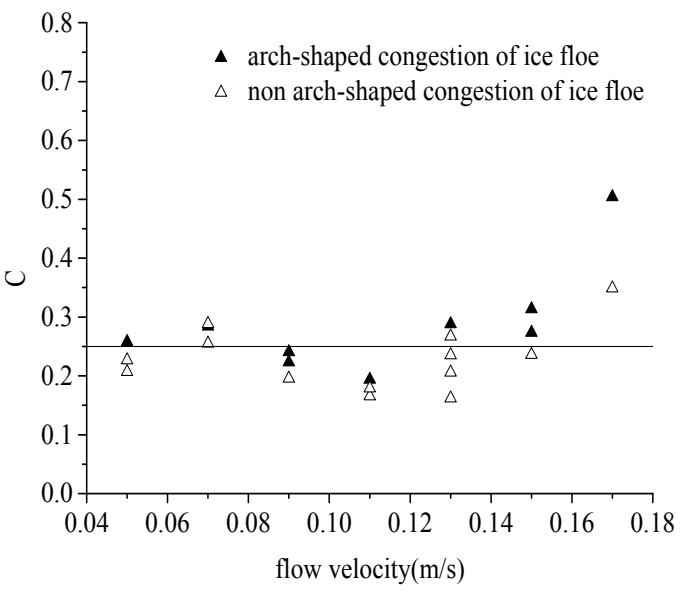

(c) $\mathrm{H}=20 \mathrm{~cm}$

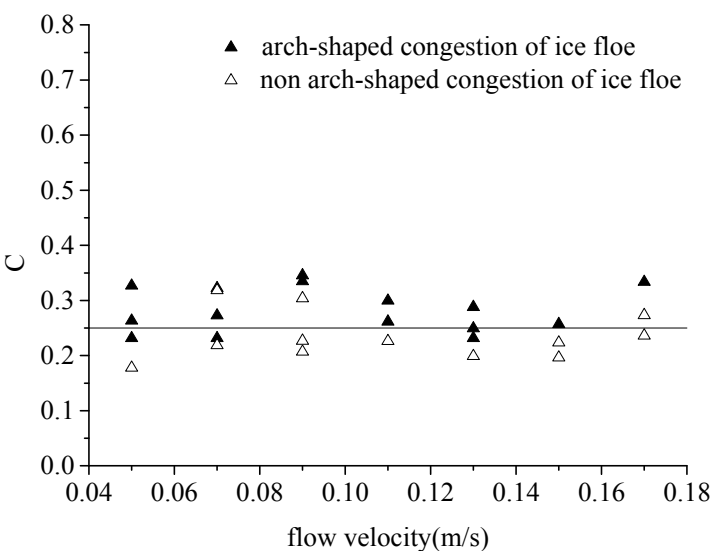

(b) $\mathrm{H}=15 \mathrm{~cm}$

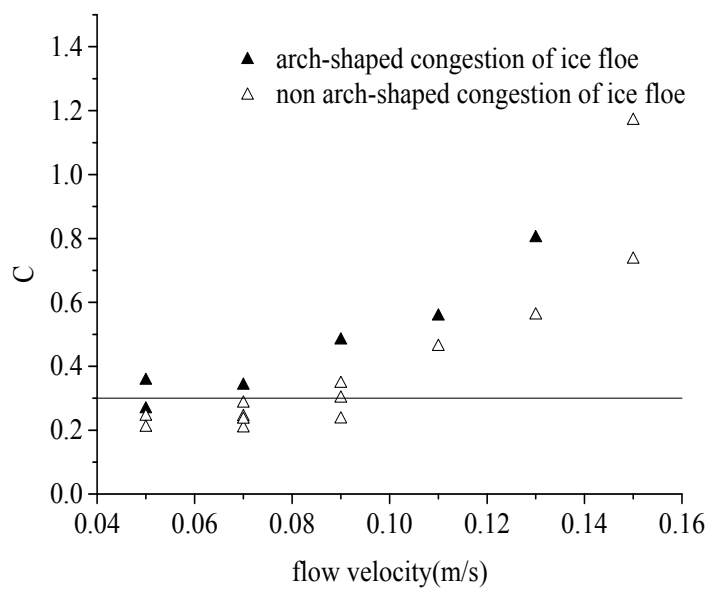

(d) $\mathrm{H}=25 \mathrm{~cm}$

Fig. 8. The relation between flow velocity and surface ice floe concentration (dimension of ice floe: $2 \mathrm{~cm} \times 2 \mathrm{~cm} \times 1 \mathrm{~cm}$ ). 


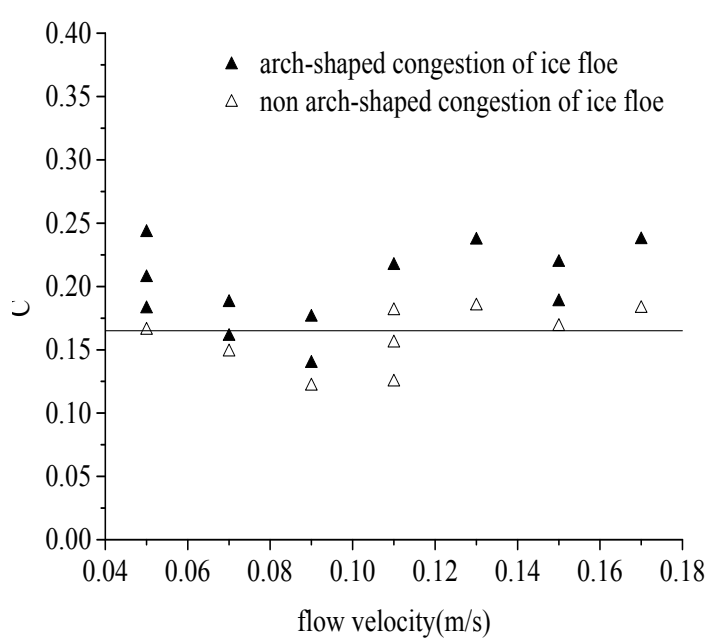

(a) $\mathrm{H}=10 \mathrm{~cm}$

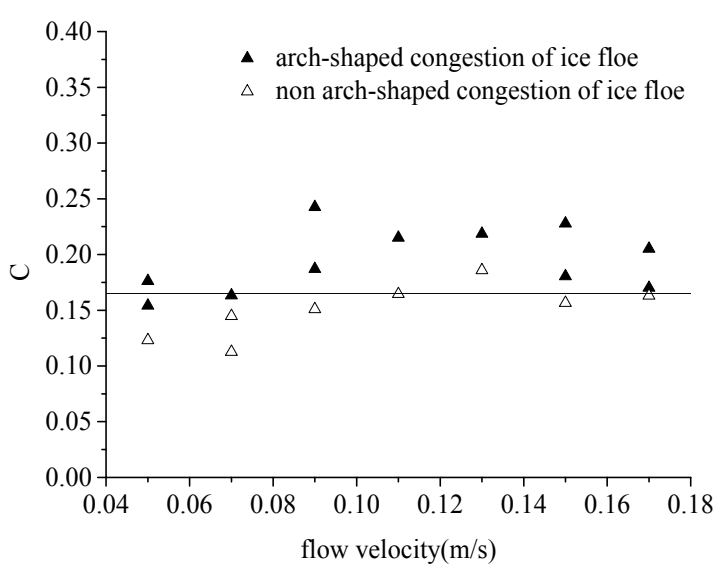

(c) $\mathrm{H}=20 \mathrm{~cm}$

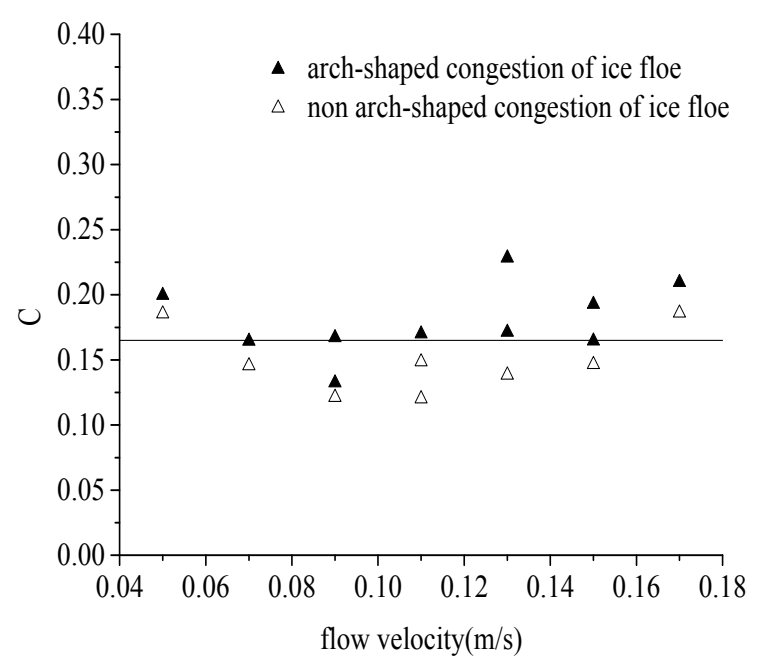

(b) $\mathrm{H}=15 \mathrm{~cm}$

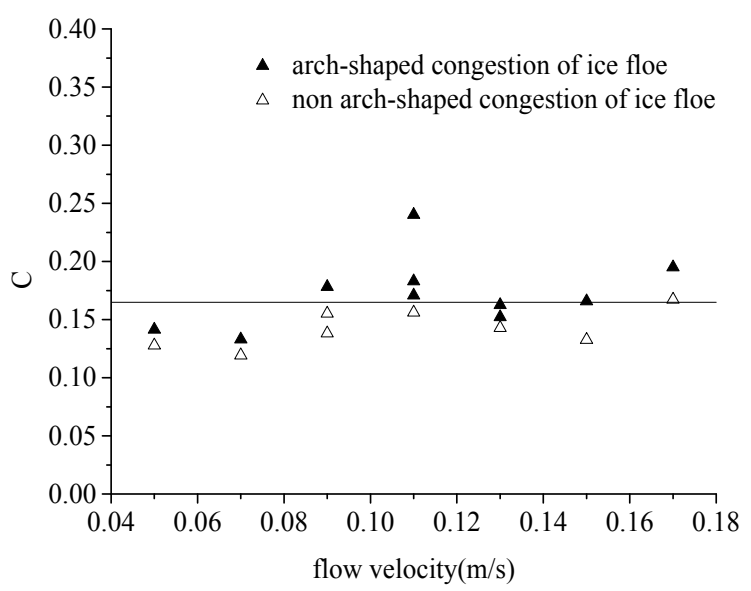

(d) $\mathrm{H}=25 \mathrm{~cm}$

Fig. 9. The relation between flow velocity and surface ice floe concentration (dimension of ice floe: $3 \mathrm{~cm} \times 3 \mathrm{~cm} \times 1 \mathrm{~cm}$ ).

Table 1. Comparison of experimental and calculated results (for critical concentration of ice floe).

\begin{tabular}{|c|c|c|c|}
\hline Data source & $\begin{array}{l}\text { Ratio of ice floe length to pier } \\
\text { distance }\end{array}$ & Experimental results & $\begin{array}{l}\text { Calculated } \\
\text { results }\end{array}$ \\
\hline Present study & 0.25 & 0.1650 & 0.1893 \\
\hline Tatinclaux and Lee (a) & 0.20 & 0.3464 & 0.3327 \\
\hline Tatinclaux and Lee (b) & 0.30 & 0.1901 & 0.2130 \\
\hline Tatinclaux and Lee (c) & 0.40 & 0.1242 & 0.1552 \\
\hline
\end{tabular}

Note: Tatinclaux and Lee (a), (b) and (c) are corresponding to the net width of contracted channel distance of $38.1 \mathrm{~cm}, 25.4 \mathrm{~cm}$, and $19.05 \mathrm{~cm}$, respectively.

\section{CONCLUSIONS}

The critical concentration of ice floe for initiating an ice cover around bridge piers has been investigated in the present study. Results show that if the concentration is less than critical concentration of ice floe, ice cover cannot be formed. Under the condition of the same pier diameter and same pier distance, the concentration of ice floe is the main factor for initiating an ice cover. Additionally, critical floe concentration has strong connection with physical characteristics of ice floe. Ice floes having larger grain size can easily result in initiating an ice cover and with a high risk for formation of an ice jam (accumulation of ice floes under ice cover). Equation for the critical floe concentration is also derived in the present research. Calculating results by using developed equation for the critical concentration of ice floe have been compared with our experimental results and data of Tatinclaux and Lee (1978). Results indicate that the calculated results by using developed equation for the critical concentration of ice floe can give reasonable prediction. Hence, the developed equation can be used to predict whether or not an ice cover will be initiated in front of bridge piers in winter time. 
Acknowledgement. The present study is sponsored by the National Natural Science Foundation of China (No. 51379054). The authors are greatly thankful for the financial support.

\section{REFERENCES}

Ackermann, N.L., Shen, H.T., 1983. Mechanics of ice jam formation in rivers. CRREL Report 83-31, U.S. Army Cold Regions Research and Engineering Laboratory, Hanover, N.H, USA.

Beltaos, S., 1995. River Ice Jams. Colorado: Water Resources Publications, LLC, pp. 105-146.

Calkins, D.J., Ashton, G.D., 1975. Arching of fragmented ice covers. Canadian Journal of Civil Engineering, 2, 4, 392399.

Carstensen, D., 2012. Flow under ice cover and jam effects. In: Proc. International Conference on Fluvial Hydraulics, River Flow 2012. San Jose, Costa Rica, pp. 1139-1144.

Kawai, T., Hara, F., Masaki, S., et al., 1997. Experimental study on the process of ice jam development. In: Proc. $9^{\text {th }}$ Workshop on River Ice, pp. 245-256.

Long, Y., Bao, S., Kuang, W., et al., 2000. Mechanics of Structures. Higher Education Press, Beijing, China, pp. 108-121.

Shen, H.T., 2010. Mathematical modeling of river ice processes. Cold Regions Science and Technology, 62, 1, 3-13.

Sui, J, Karney, B., Sun, Z., Wang, D., 2002. Field investigation of frazil jam evolution - a case study. ASCE Journal of Hydraulic Engineering, 128, 781-787.

Sui, J., Karney, B., Fang, D., 2005. Variation in water level under ice-jammed condition - Field investigation and experimental study. Nordic Hydrology, 36, 1, 65-84.

Sui, J., Wang, J., He, Y., Krol, F., 2010. Velocity profiles and incipient motion of frazil particles under ice cover. International Journal of Sediment Research, 25, 1, 39-51.

Tatinclaux, J.C., Lee, C.L., 1978. Initiation of ice jams - a laboratory study. Canadian Journal of Civil Engineering, 5, 2, 202-212.

Tyminski, T., 2010. Hydraulic model research on bridge piers based on the example of selected bridges in Opole. Rocznik Ochrona Srodowiska, 12, 879-893.

Urroz, G.E., Schaefer, J., Ettema, R., 1994. Bridge-pier location and ice conveyance in curved channels. Journal of Cold Regions Engineering, 8, 2, 66-72.
Wu, P., Hirshfield, F., Sui, J., 2014. Further studies of incipient motion and shear stress on local scour around bridge abutment under ice cover. Canadian Journal of Civil Engineering, 41, 10, 892-899.

Wu, P., Hirshfield, F., Sui, J., 2015. Local scour around bridge abutments under ice covered conditions- an experimental study. International Journal of Sediment Research, 30, 1, $39-47$.

\section{NOMENCLATURE}

$b$ ice floe width,

$B$ flume width,

$C$ ice floe concentration,

$C_{D}$ coefficient of dynamic pressure,

$C_{s}$ drag coefficient from water,

$C_{s}$, drag coefficient from wind,

$C^{*}$ critical ice floe concentration,

$f$ friction,

$f_{c}$ cohesive force,

$F$ dynamic pressure,

$F_{d}$ drag force,

$F_{d}^{\prime}$ drag force by wind,

$G$ ice floe gravity,

$h$ water depth in front,

$k_{0} \quad$ horizontal pressure coefficient,

$L$ ice floe length,

$Q_{i}$ ice discharge,

$s_{i} \quad$ specific density of ice floe,

$t$ ice floe thickness,

$v$ upstream flow velocity,

$v$ ' wind velocity,

$\beta$ contraction coefficient caused by piers,

$\lambda$ ice friction coefficient,

$\rho_{i}$ mass density of ice,

$\rho$ mass density of water.
Received 4 March 2015

Accepted 19 August 2015

Note: Colour version of Figures can be found in the web version of this article. 